\title{
Universitas Komputer Indonesia Students' Understanding of the Types of Online Advertising in Meeting Their Information Needs
}

\author{
Desayu Eka Surya ${ }^{1 *}$ H Hermawan ${ }^{2}$ \\ \{ desayuekas1012@email.unikom.ac.id¹ ${ }^{1}$,helmiher1997@mahasiswa.unikom.ac.id² $\}$ \\ Departemen Ilmu Komunikasi, Universitas Komputer Indonesia, Indonesia ${ }^{1}$ \\ Fakultas Teknik dan Ilmu Komputer, Universitas Komputer Indonesia, Indonesia ${ }^{2}$
}

\begin{abstract}
Marketing in online media is the activity of delivering information about certain products by utilizing media accessed through the internet network. Online media marketing with the provisions of online advertising is published on various pages of websites. Although online media is said to be an effective medium in advertising, it is important to know the types of online advertising that can meet prospective customer information. The purpose of this research is to find out the type of online advertising and its understanding to prospective consumers in obtaining information. The method used in this study is a qualitative approach with descriptive research method to determine the understanding of types of online advertising that can meet consumer information needs. This research was carried out by Universitas Komputer Indonesia students on several websites that contain online advertisements. Relevance and impact clearly show that online ads that are packaged attractively and contain information as needed can illustrate the understanding of consumers to attract consumer buying interest.
\end{abstract}

Keywords: Advertising, online advertising

\section{Introduction}

The growth of online advertising in Indonesia has the potential to increase along with technological developments and the high activity of people in online transactions. As reported by Ekonomi.bisnis.com, research from Google Temasek in 2017, e-commerce transactions reached USD 10.9 billion in Southeast Asia. This amount is $41 \%$ greater than in 2015 which only reached USD 5.5 billion. The community began to adapt and utilize the presence of online media to carry out product marketing activities because it was considered to be more effective and efficient. Increasingly widespread buying and selling activities in online media are because lifestyles tend to be consumptive, making the opportunity for online advertising present as a new media in advertising with a wider range. This trend is used by marketers by offering various sales promotions, low-priced systems at the beginning, ease in trying and consuming other products. [1] There have been many online media that contain the information of the marketed product. The forms of advertising may vary whether in the product-specific website only or appear on some parts of the website such as classified ads. Online advertising is generally used to boost sales as a form of marketing (social media marketing). The purpose of this research was to find out the understanding of the community, especially Unikom students about various 
types of online advertising in fulfilling their information needs. According to the research made by Franco and Nancy, there are several advantages in advertising products on the internet that are not present in traditional advertising media [2]. Although online media is known as a borderless media because it can reach a wide range of consumers, in the realm of marketing, it is important to know what types of online advertising can provide information to prospective consumers.

According to Soegoto, advertisements are promotional media used by companies to introduce and notify products or services offered by them to prospective buyers. [3]. Kumar and Raju describe advertising as communication, marketing, economic, social, persuasion, and public relations processes. Several ways are identified in advertising and expected to provide information and introduce certain products to prospective buyers. [4]. Evans explained that advertising on the internet has some differences with traditional advertising. [5]. The difference in question lies in checking the prospective buyers. If online ad checking is done based on the traffic location of the producer and ad network, the number of prospective buyers who visits their site at a certain time can be found out. While traditional advertising is more limited to digging deeper into certain products or the physical store. According to Anusha, advertising on the internet has become a must in business today. Especially for those who want to promote their products and to be known by many people because the usage of the internet is not only for entertainment or just looking for information [6]. According to Tavor, Advertising on the internet is more attractive to consumers because the display of advertisements on the internet is unique and diverse [7]. According to Terkan, Advertising on the internet has several benefits. For example, it can help consumers to save time by directing them to the preferred products. Advertising on the internet can also provide information to consumers about new products easily and quickly [8].

Online advertising is included in the context of mass communication. According to Bittner, mass communication is the delivery of messages communicated through the mass media to a large number of people. This means that mass communication occurs when there are mass media such as television and newspaper as an intermediary along with the development of the internet age into the mass media category. This research is supported by the theory of mass media effects because the message of online advertising needs to be understood by consumers through a selectivity process that consists of three stages. According to Morrisan, the criticality of someone's message is stated that mass media has limited effects and audiences are not easily influenced by the contents of the message. The principle of selective process theory consists of three principles, namely the first stage of selective acceptance of information. Both selective and third perceptions of selective memory and advertisements are said to be successful if remembered by the audience. People who use online media will often be exposed to online advertising and have an impact on consumer's thoughts. According to Sciffman and Kanuk asserted consumer behavior in finding, buying, using, evaluating, and spending products and services in the hope that they will satisfy their needs [9].

\section{Method}

The data in this study were obtained through interviews conducted by Unikom students relating to their understanding of the types of online advertising and the benefits they felt from online advertising. Informant selection is determined based on the technique of withdrawal of the informants by purposive sampling which also called sampling consideration. According to 
Dr. Riduan, M.B.A in his book The Basics of Statistics stated: "Purposive sampling is a sampling technique used by researchers if researchers have certain considerations in taking samples or informants for specific purposes. Only those who are experts and who should give consideration for the taking of informants are needed. Therefore, this sampling technique is suitable for case studies where the aspects of a single case representative are observed and analyzed [10]. To obtain research data, a qualitative approach is carried out with descriptive methods.

Qualitative research is carried out in nature and exploration conditions. In qualitative research, researchers are the key instruments. Therefore, the researchers must have extensive theoretical and insightful provisions to be able to ask, analyze, and construct the object under study to become clearer. In this approach, the researchers make a complex picture, examine words and detailed reports from informants' views, and also conduct studies on natural situations [11]. According to Sugiyono descriptive method is a method used to provide an overview or analysis of a research result but is not used to make broader conclusions [12]. While descriptive studies according to the Qualitative Research Methodology book, namely data collected in the form of words, images and not numbers. The three types of data are due to the application of qualitative methods. So that all that is collected is likely to be the key to what has been studied [13].

The descriptive method in this study is to find out the understanding of Unikom students about the types of advertisements on the internet that can meet their information needs. The sample population in this study is Unikom students who are still actively studying, consisting of 2015-2018 classes. To get more accurate data on respondents' understanding of the problems being studied, the study sample was taken as many as three people. Research data is collected by conducting observations, interviews, literature reviews, archive records, documentation, and internet searching. Furthermore, the collected data is processed and analyzed according to the stages proposed by Nasution, namely: Data Presentation, Data Reduction, Data Display (Display Data) and Conclusion Withdrawal / Verification. To test the validity of the data or conclusions from the results of the verification, it is re-examined on the collected data and discuss with colleagues and increase perseverance. The next steps are needed to analyze the data that has been obtained. An activity that refers to the systematic review or testing of a matter to know the parts, the relationships between parts, and the relationship of parts to the whole.

\section{Results and Discussion}

The results of this study were obtained based on the background of the described situation so that the research problems were formulated as follows: "How is the Understanding of Unique Students about the Types of Online Advertising in Meeting Their Information Needs?". Furthermore, the question is described in the following points:

1. How do students know the types of online advertising?

2. What benefits do students feel by using online advertising?

The results of his research that there are several types of advertisements that respondents often see on the internet as follows. 


\subsection{Student Knowledge about Types of Online Advertising}

Based on the results of the research through observations and interviews, the following are some types of online advertising that are known and understood by respondents and are equipped with several examples posted by the website:

a. Floating Ads

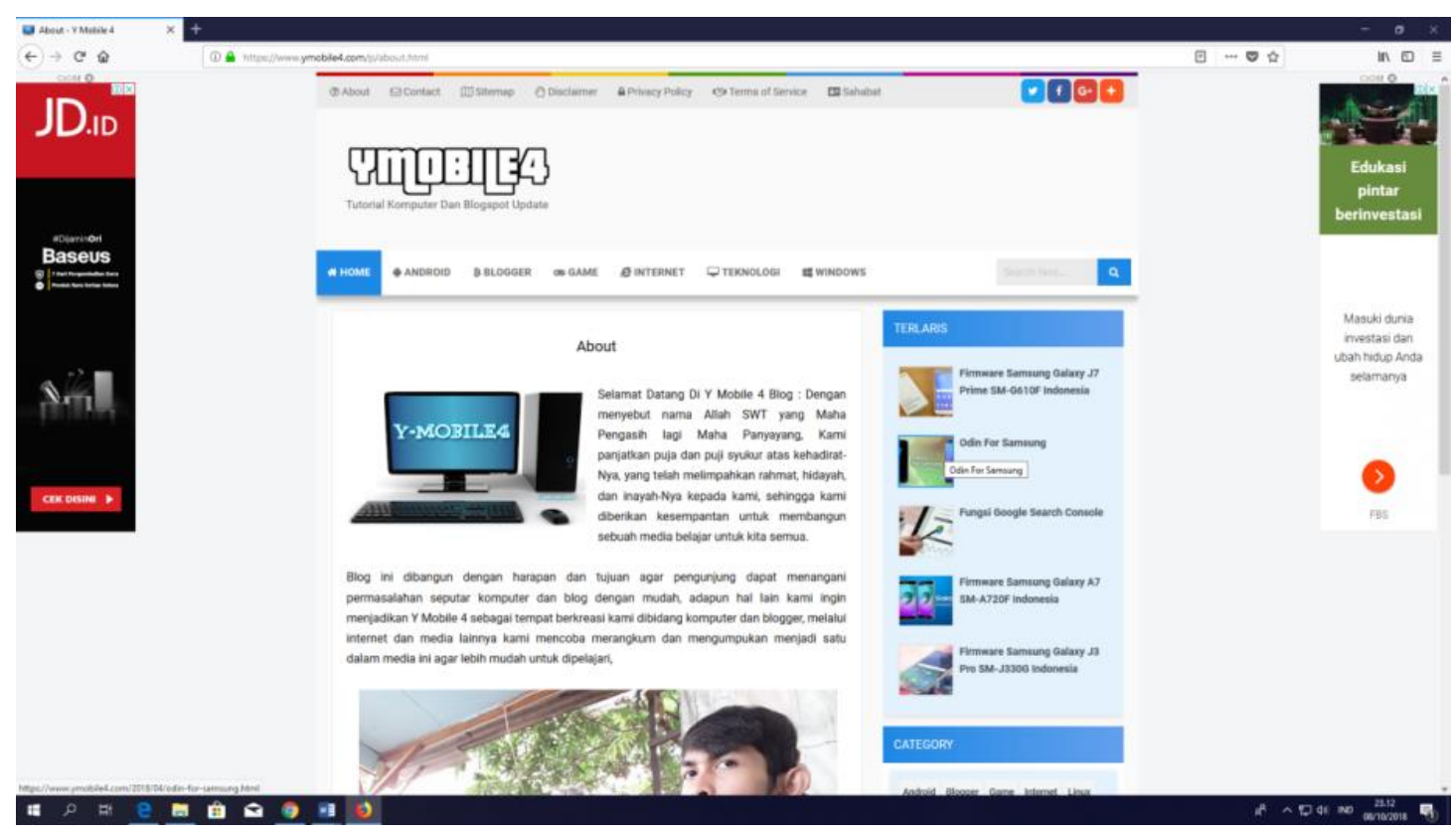

Fig. 1. (Floating Ads)

Like Floating Ads, Direct Ads, Self-Service Ads, In-Text Ads, Video Ads and Pop-Up Ads. Advertising has its own charm to attract buyers. With differences in advertising, consumers can sort out what they think is interesting and which are not interesting. (Figure 1).

Following are examples of floating ads on websites, ads can disappear by themselves after a certain period of time (usually 5-30 seconds) or we (users) can also click close ads. Drift ads usually only appear on the top, bottom, left, or right of the website pages and do not interfere with the appearance of the web. As in the picture above, the ad position is on the left and right of the website. Placement in this ad is very neat and does not interfere with the appearance of the web.

\section{b. Direct Advertising}

Direct Advertising is advertising where advertisers and website owners are directly related. This website is devoted to displaying advertisements so that it can be seen that the ad is placed in its position. So consumers who visit this website are looking for the products they need.(figure 2) 


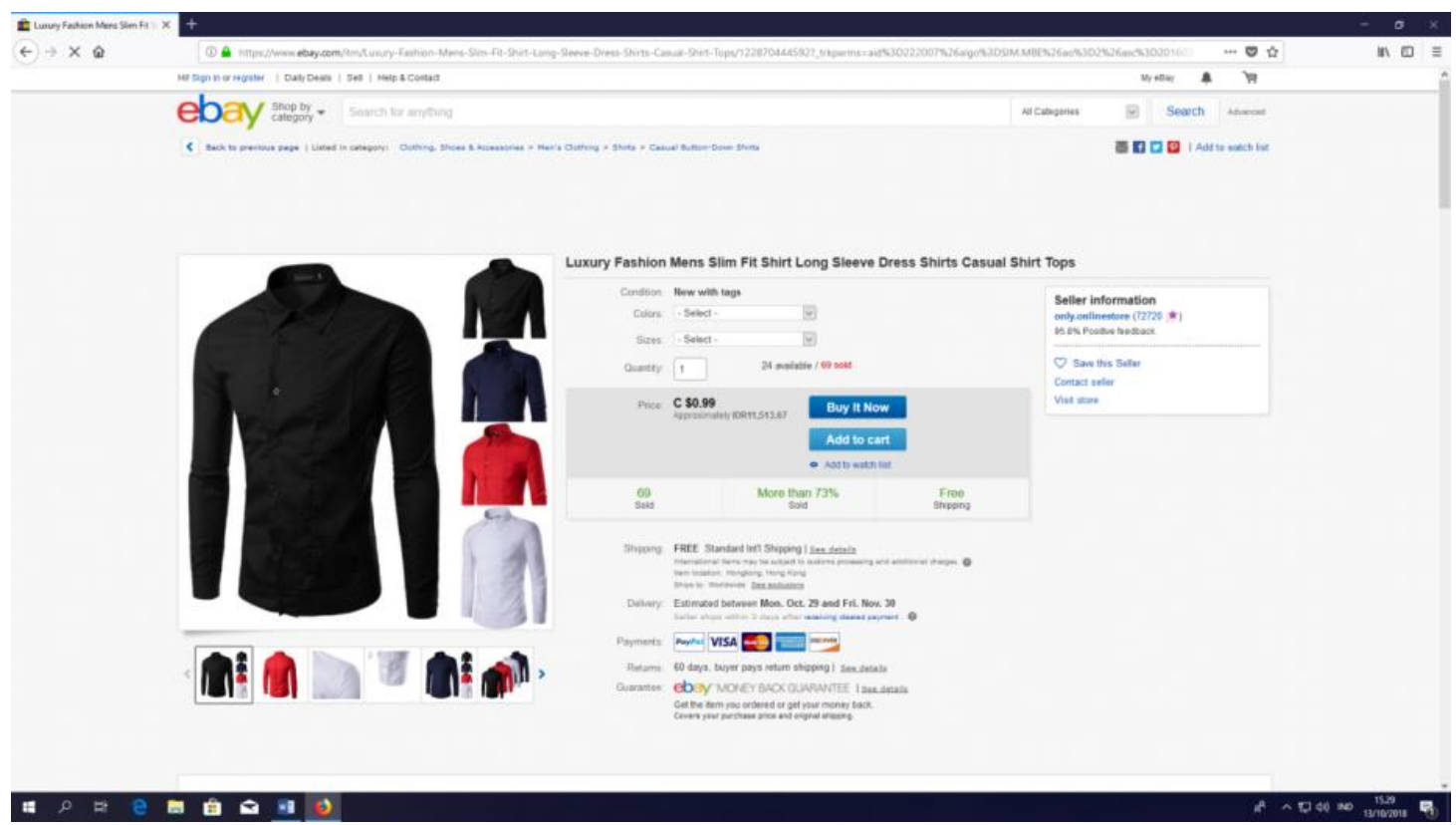

Fig. 2. (Direct Ads)

c. Self-Service Advertising

Self-Service Advertising is an ad that is done and installed is an item of its own product. Advertisers are free to determine how many ads and the appearance of the ad itself starting from the color, text, and position made by the manufacturer who owns the website (Figure 3 ).

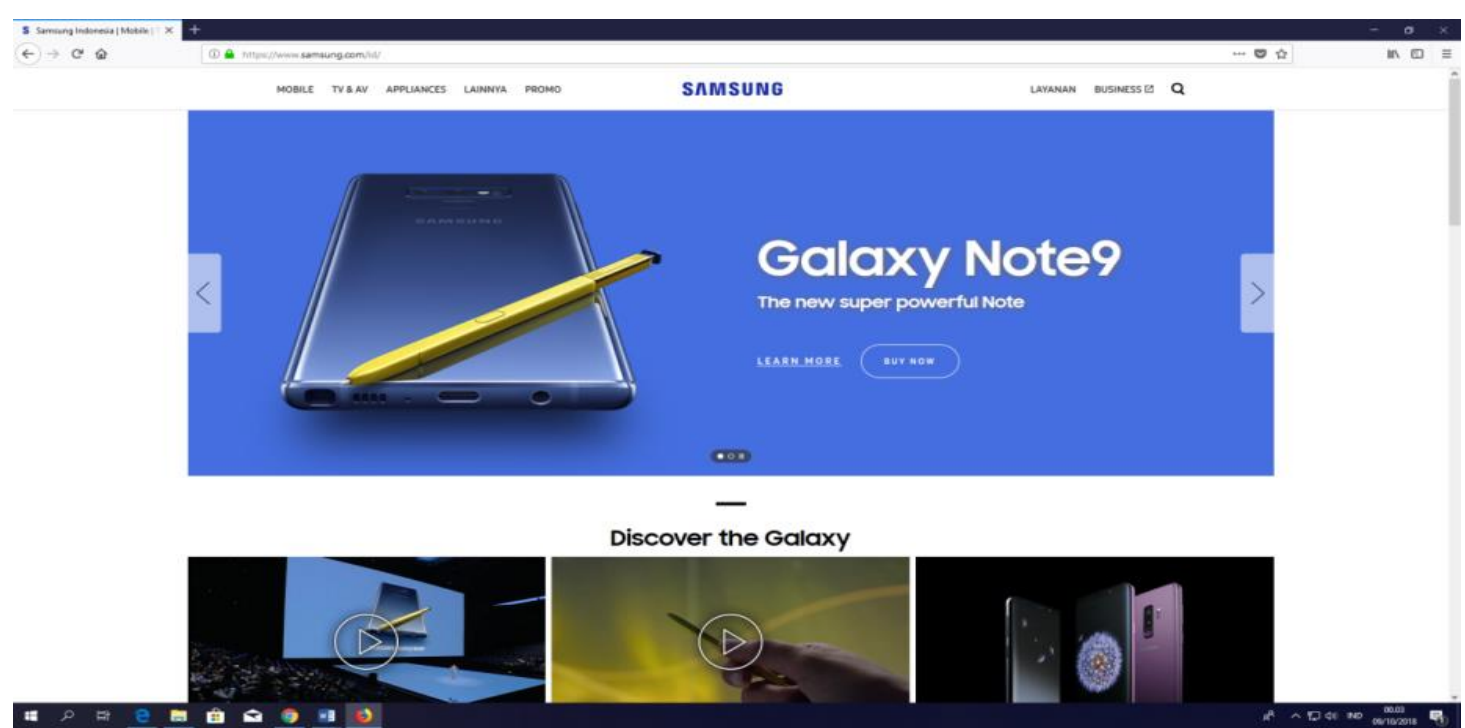

Fig. 3 (Self-Service Ads) 


\section{d. In Text Advertising}

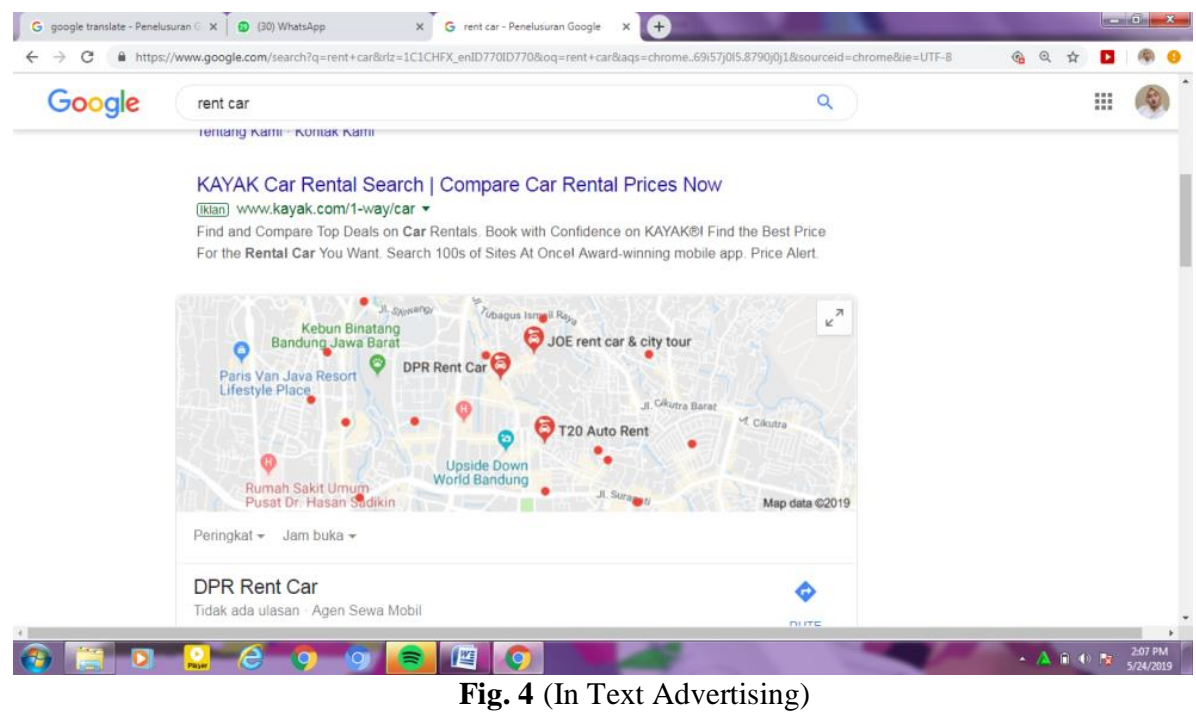

In Text Advertising is a type of ad that automatically connects certain words on a website with related advertising content. This ad can be seen more quickly by potential customers because it is usually in the top position. Like the picture above when I wrote the word "Rent a Car" then there is an ad associated with the sign "ad". The web site that is played will be related to the word we wrote.(Figure 4)

\section{e. Video Advertising}

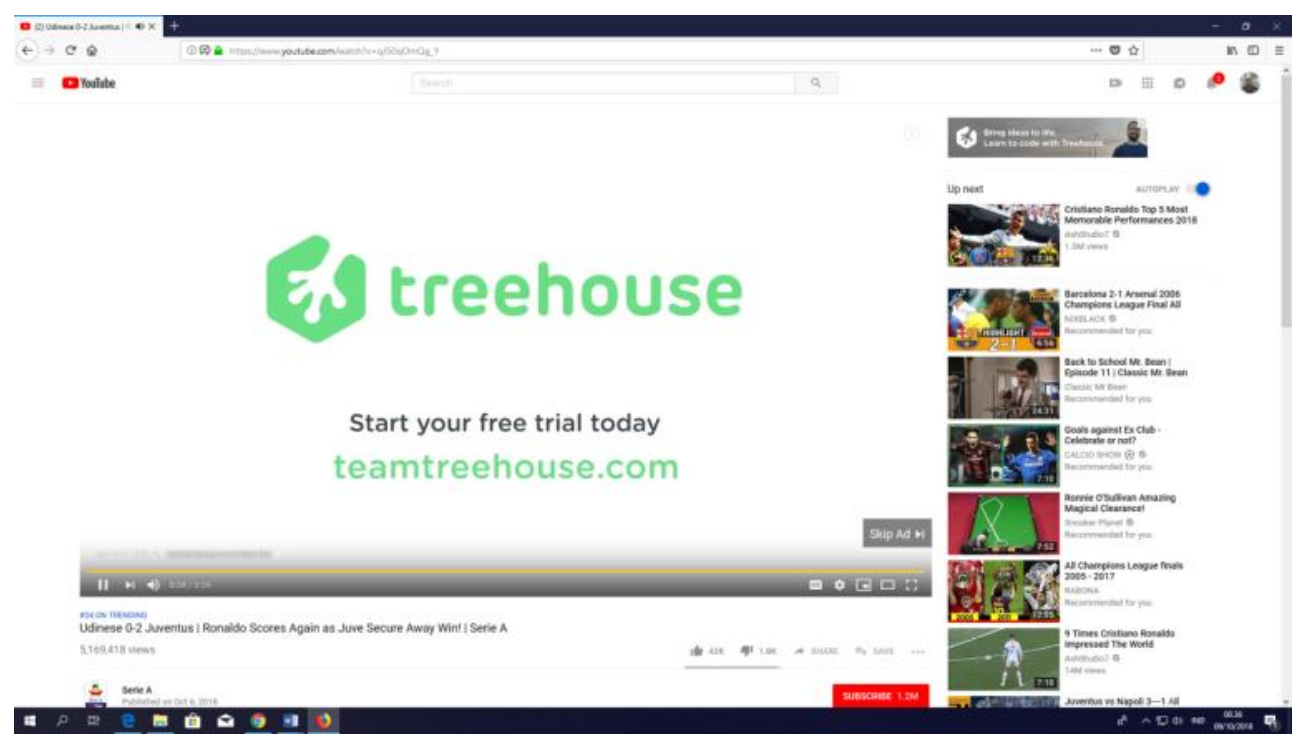

Fig. 5. (Video Advertising) 
Video Advertising is an ad in the form of a video. Usually these ads are targeted at video content and usually these ads can be closed after a certain period of time ( usually 3- 5 second ) or there is can't do it at all before the ad is finished. If someone visit to the website and see an ad like that, visitors usually more focus on the video that will be seen and tend to ignore the ad.(Figure 5)

\section{f. Pop Up Advertising}

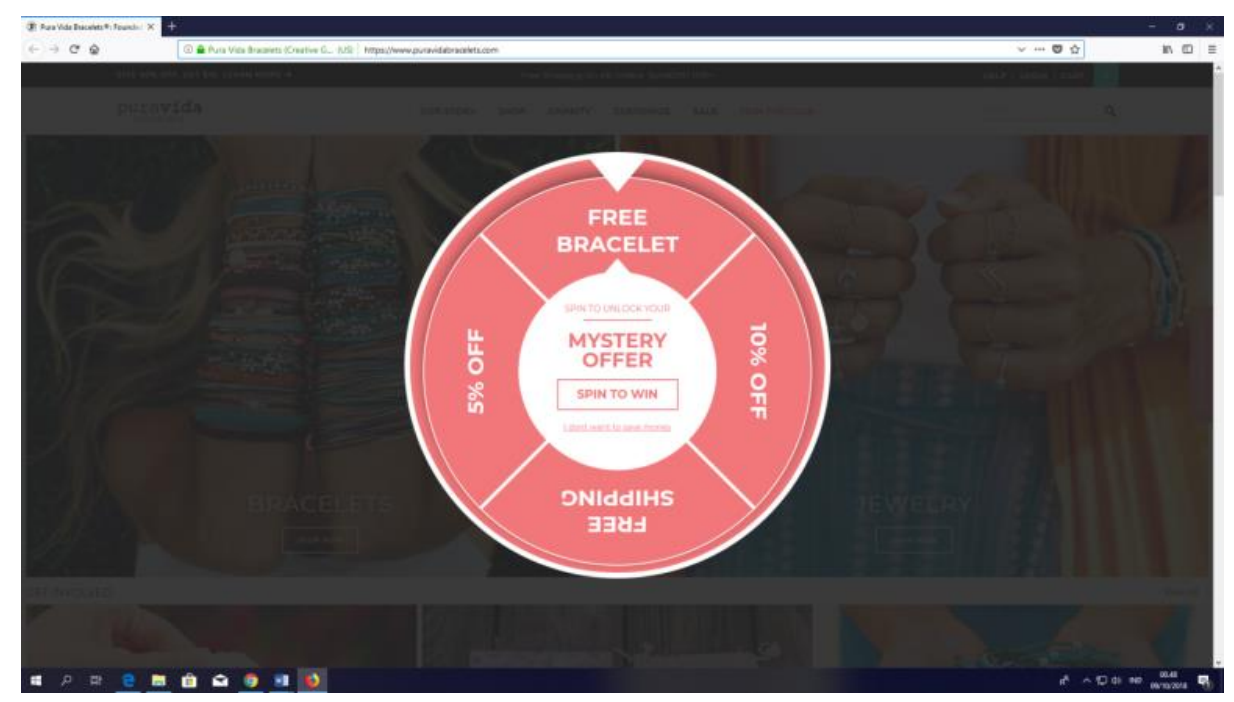

Figure 6. (Pop-Up Advertising)

Pop-Up Advertising is an advertisement that usually appears suddenly when we first open a certain website. The size of this ad is varies, some cover the entire contents of the website, some are only convering part of website. Usually ads like this are less attractive to potential customers because it feels irritating.(Figure 6)

\subsection{Benefits of Students by Using Online Advertising}

Many online advertisements appear when accessing social media even each ad has its own characteristics. As a means of introducing products in the hope of boosting sales, as well as possible, packaged ads are attractive without putting aside information on the products offered. The six types of online advertising that are known by respondents each have their own characteristics so that they provide different benefits. For example, floating ads and pop-up advertisements, are often seen as annoying to website visitors. But the nature is more flexible because floating ads can appear on various websites so that they are increasingly seen by online media users.

Meanwhile direct advertising tends to be more complete in loading information so that many people consider it easier to obtain information through this type of advertising. Similar benefits are also felt when looking at independent advertisements because the appearance of advertisements is very supportive starting from the color, text, and position performed by the manufacturer who owns the website. 


\section{Conclusion}

Advertising is one of the promotional media to market products targeted at consumers to attract buying interest in the products offered. The strategy commonly used by producers in marketing their products through advertising media on the internet because it feels more efficient and right on target.The progress of this technology can make it easier for consumers to find the products they want.

\section{References}

[1] Widianti, U. D., Harihayati, T., \& Sufaatin, S. : Risk project management analysis. In IOP Conference Series: Materials Science and Engineering (Vol. 407, No. 1, p. 012087). (2018).

[2] Franco, C. E., \& Nancy, U. A. : Effectiveness of Online Advertising in Tirunelveli District. International Journals of Research in Management \& Business Studies (IJRBMS 2017),4(3), pp. 44-47. (2017).

[3] Soegoto, E. S., \& Siddiq, I. F. : Development of online ticket system at a football club in Bandung, Indonesia. In IOP Conference Series: Materials Science and Engineering (Vol. 407, No. 1, p. 012049). (2018).

[4] Kumar, D. P., \& Raju, K. V. : The Role of Advertising in Consumer Decision Making. IOSR Journal of Business and Management (IOSR-JBM),14(4), pp. 37 - 45. (2013).

[5] Evans, David S. : The Online Advertising Industry: Economics, Evolution, and Privacy. Journal of Economic Perspectives, 23(3), pp. 37 - 60. (2009).

[6] Anusha, G. : Effectiveness of Online Advertising. International Journals of Research Granthaalayah, 4(3), pp. 14 - 21. (2016).

[7] Tavor, T. : Online Advertising Development and Their Economic Effectiveness. Australian Journal of Business and Management Research, 1(6), pp. 121 - 133. (2011).

[8] Terkan, R. : Importance of Creative Advertising and Marketing According to University Students' Perspective. International Review of Management and Marketing, 4(4), pp. 239 - 246. (2014).

[9] Soegoto, E. S. (2018, August): Implementing Laravel framework website as brand image in higher-education institution. IOP Conference Series: Materials Science and Engineering (Vol. 407, No. 1, p. 012066). IOP Publishing.

[10] Soegoto, E. S., \& Akbar, R. : Effect of the internet in improving business transactions with online market methods. In IOP Conference Series: Materials Science and Engineering(Vol. 407, No. 1, p. 012051). (2018).

[11] Creswell, John W. : Qualitative Inquiry and Research Design, Choosing Among Five Traditions. California: Sage Publication. (1998)

[12] Warlina, L., \& Ambara, J. P. : Information System in Promoting and Ordering of Webbased Confection Service. IOP Conference Series: Materials Science and Engineering (Vol. 407, No. 1, p. 012047). (2018).

[13] Soegoto, E. S., \& Rafi, M. S. F. : Internet role in improving business transaction. IOP Conference Series: Materials Science and Engineering (Vol. 407, No. 1, p. 012059). (2018). 